\title{
VERTICAL EXPANSIONS: Assessing the Feasibility of Building Private Residential Space Atop Existing Public Community Centres and Libraries through a Public-Private Partnership in Toronto's Inner- Suburbs
}

by

Pirijan Ketheswaran
B.Sc, UofT, 2007

A Major Research Paper

presented to Ryerson University

in partial fulfillment of the requirements for the degree of Master of Planning in Urban Development

Toronto, Ontario, Canada, 2011

(c) Pirijan Ketheswaran 2011 


\section{Author's Declaration}

I hereby declare that I am the sole author of this major research paper.

I authorize Ryerson University to lend this paper to other institutions or individuals for the purpose of scholarly research.

Signature

I further authorize Ryerson University to reproduce this paper by photocopying or by other means, in total or in part, at the request of other institutions or individuals for the purpose of scholarly research.

Signature 


\section{Abstract:}

The aim of this study is to analyze the feasibility of building private residential space on top of existing publicly-owned inner-suburban Toronto community centres and library buildings through a public-private partnership.

The numerous benefits and feasibility of these 'vertical expansions' to the community and government is validated by the potential ability to increase local access to services, compatibility with wider government planning objectives such as smart growth, and by the capacity to kickstart a virtuous economic cycle to increase quality of place. The appeal to private developers is demonstrated through considerations of the market, money, production, people and environment.

Pilot sites where vertical expansions could best succeed are identified based on facility type, 'city 3' suburban status, potential marketability, and basic physical \& structural considerations. 16 pilot sites were identified, which were further refined based on property value to identify the pilot sites with the highest potential for success.

A model for a reductionist and mutually equitable $\mathrm{P} 3$ arrangement for both the development and post-construction management was proposed and informed by the literature review of past $\mathrm{P} 3$ case studies.

\section{Key Words:}

Public-Private Partnerships (P3s), Suburban Planning, Community Services

\section{Acknowledgements:}

l'd like to thank Professor Jane Hao (PhD, HK Poly.) for her invaluable role in Supervising my research and the writing of this paper. As well as Professor David, Amborski (M.Sc, M.A., UofT) for his efforts and input as my Second Reader. 


\section{Table of Contents}

Chapter 1 - Introduction

- 1.1 Introduction to the Research Problem

- 1.2 Aim and Objectives

- 1.3 Methodology

- 1.4 Significance

Chapter 2-Literature Revlew

- 2.1 A recent history of the use of P3s in Ontario

- 2.2 Why is Ontario Investigating to P3 Delivery?

- 2.3 The Success of P3 Overseas

- 2.4 Current Public Opinion of P3s in Ontario

- 2.5 The Additional Challenges of Air Rights Developments

- 2.6 Post-Construction P3 Management Issues

Chapter 3 - The Feasibility of Vertical Expansions

- 3.1 The Benefits of Vertical Expansions to Both Local Community and Wider Urban Planning Objectives

- 3.2 Evaluating Private Sector Feasibility using the Bontje Model

- 3.3 Specific Considerations are Needed for Projects to Avoid Implementation Barriers

- 3.4 Site Selection Criteria and Results

Chapter 4 - Proposed P3 Design

- 4.1 General Arrangement of the P3 used in Vertical Expansions to Ensure Equity

- 4.2 Additional Considerations Made to Avoid Potential Pitfalls

- 4.3 How P3 Success will be Evaluated

Chapter 5 - Analysis and Discussion

Chapter 6 - Conclusions and Recommendations (Further Studies) 46

- 6.1 Conclusions

- 6.2 Recommendations

- 6.3 Areas for Further Study 


\section{Chapter 1}

\section{Introduction}

\subsection{Introduction to the Research Problem}

Public libraries and community centres are integral to the identity of suburban communities and function as critical and well utilized social and recreational centres (Urban Libraries Council, 2011). The programs provided by these public institutions produce tremendous social, health and learning benefits to community participants.

However, particularly for residents in less advantaged suburban neighbourhoods, continued population growth, changing demographics, aging facilities and severe underfunding create barriers to access. The situation these barriers have created for public access to community services is described by Clutterbuck and Howarth (2002) as 'Toronto's Quiet Crisis', that specifically includes:

- Service demands that exceed supply

- Unaffordable user fees

- Not enough programs for youth and seniors

- Increasing rental costs for community social functions

- Building closures and service interruptions 
Improving access requires ongoing investment. Unfortunately, such investments have fallen drastically short of the levels required to maintain states of good repair, much less to expand service capacity to projected levels of new demand. To illustrate the extent of this problem, the total Toronto Parks and Recreation maintenance backlog for 2010 is estimated at $\$ 261.04$ million, and is projected to be $\$ 329.310$ million in 2015 and $\$ 400.636$ million by 2020 . Currently, service quality is being maintained through an increasing reliance on debt which constitutes $59 \%$ of the Toronto Parks and Recreation recommended Budget (Toronto Parks and Recreation, 2011).

Clearly an alternative way of funding community services is needed. Public-Private Partnerships (P3s) - which are defined as a cooperative venture between public and private actors utilizing the expertise of each partner to best meet public needs through the equitable allocation of resources, risks and rewards - is an increasingly popular solution to larger-scale infrastructure deficit in Canada (Canadian Council for PublicPrivate Partnerships, 2011).

The ideal P3 solution would provide public benefits by enabling libraries and recreation centres to be able to increase the capacity of public services, increase the selection of programs offered, expand operating hours, reduce or eliminate user fees, fund energy efficiency upgrades and the good maintenance and enhancement of facilities. This ideal P3 solution would also have to provide benefit to private sector profitability. 
The P3 arrangement proposed in this study involves the construction of private residential space on top of existing publicly-owned community assets (henceforth termed 'vertical expansions') to provide funds that relieve public maintenance needs and allow for expansion of services.

The specific benefits that a vertical expansion $\mathrm{P} 3$ gives to private sector profitability is the ability to utilize the pre-existing built-form redundancies of these community buildings which they will not have to build themselves. These redundancies include, large parking lots, utilities infrastructure and amenities, such as recreation rooms and common areas. Developers would also benefit from the marketable locational advantages of these sites which are commonly located near other desirable amenities such as shopping malls, schools, and parks (quantitatively demonstrated in Chapter 3 using Geographic Information Systems (GIS) Analysis).

\subsection{Research Aim and Objectives}

The aim of this study is to analyze the feasibility of building private residential space on top of existing publicly-owned inner-suburban Toronto community centres and library buildings through a public-private partnership.

In order to attain the aim, five research objectives are set out as follows: 
- Validate the feasibility of vertical expansions to all stakeholders through the literature review

- Developing a model for the arrangement of a reductionist P3 arrangement for vertical expansions, how P3 pitfalls can be avoided, and how success will be evaluated.

- Using quantitative spatial criteria, identify possible target sites where vertical expansion projects could best succeed.

- Develop a set of guiding principles for the practical implementation of vertical expansions

- Draw conclusion and make recommendations 


\subsection{Research Methodology}

Stage 1 - Validate the feasibility of vertical expansion projects to all stakeholders

Through a comprehensive literature review, the advantageousness, barriers and feasibility of vertical expansion projects will be established for the involved stakeholders - particularly the local community, private developers and municipal decision makers.

\section{Stage 2-Developing a model for the vertical expansion P3}

Using case studies of P3 application the general P3 arrangement governing vertical expansions to ensure equity will be proposed. Following this, the three primary ways in which P3s, particularly those featuring ancillary development, can fall prey to private capture will be described and the case will be made for how simple and reductionist contract design and administration can be used to mitigate risks.

Stage 3 - Identifying the most effective potential pilot sites for vertical expansion This section will use a quantitative selection criteria (based on asșumptions supported by the literature) to identify the specific public building sites where there is most need for service capacity enhancement, which have potentially marketable locational advantages and are physically amenable to cost-effective vertical expansion projects. 


\section{Stage 4 - Guiding Principles for the field implementation of vertical expansions}

The fourth stage of the research will involve a distillation of the secondary research and previous sections regarding the community perception of services, private sector risk assessment, municipal barriers, and P3 contract design. In order to develop a series of guiding principles for the practical implementation of vertical expansions that should guide future development and design. This stage can also be thought of as further discussion.

\section{Stage 5 - Conclusions and Recommendations}

The research aim will be restated, and the arguments in favor of vertical expansions as a feasible alternative to alleviate the insufficient funding of community services will be briefly recapped. Finally, directions and recommendations for next steps and future research opportunities will be provided.

\subsection{Research Significance}

It is anticipated that this study will reveal new knowledge and improve understanding for decision makers contemplating smaller scale, single-facility based P3 arrangements. The proposed P3 management model of the new shared facility created through the vertical expansion project is purposefully reductionistic to clearly state roles and responsibilities in order to avoid complications and mismanagement that could 
otherwise occur. The requirements of public actors to ensure the creation of successful partnerships and how success can be measured is also outlined.

Furthermore, vertical expansion projects increase density in established inner-suburban neighborhoods where infill opportunities are scarce and, in the longer term, strongly contribute to smart growth objectives. In such a way can these interventions serve as urban acupuncture to stimulate a virtuous cycle including higher quality urban design, increased local business activity and increased residential density in Toronto (JunJie, 2010 and Canadian Urban Institute, 2005) 


\section{Chapter 2}

\section{Literature Review}

\subsection{A Recent History of the Use of P3s in Ontario}

While still in the early stages of application, the history of P3s in Ontario has not been a positively storied one. One of the earliest and most publicly infamous examples of a P3 being used in Ontario was for the Brampton Civic Hospital, where the government paid a private consortium to design, build and finance a hospital, and to provide nonclinical services such as laundry, food and security. Reported on by (Gilbert, 2009), the end result of which is that the hospital has ballooned to double the promised cost with only three-quarters of the promised beds. According to Auditor General Jim McCarter (2008), Ontario could have saved over $\$ 100$ millions dollars if the Brampton Civic Hospital had been built and operated using traditional public procurement methods instead of a P3. The government agency responsible for overseeing the P3 has been fairly criticized for its lack of openness and transparency, particularly regarding its value-for-money assessments and audits.

Today, almost all P3 hospitals are in a serious deficit position. According to Canadian Business (2005), the evidence shows that the problems of using a P3 to build and run a hospital will always be endemic to a model that requires very high borrowing costs and very high profit requirements. 
Most recently, the mayor of Toronto, Rob Ford, has proposed to Metrolinx, the regional transit authority that an extension of the Sheppard Subway Line be designed, financed and built though a P3.

\subsection{Why is Ontario Investigating to P3 Delivery?}

According the a P3 'Primer' published by the Ontario Association of Architecture (OAA, 2003), the recent popularity of exploring P3s for infrastructure and service delivery in Ontario is connected to a number of long accruing circumstances. The first factor is a result of long-term infrastructure neglect - Existing infrastructure needs to be upgraded and new infrastructure needs to be created for a rapidly growing economy and population. Infrastructure construction for both existing and new demand is estimated to cost Ontario between $\$ 40$ to $\$ 60$ billion just to become current. However, in the face of this huge demand, we continue to be told that there is simply not enough money to address the infrastructure gap through traditional methods.

Using P3 for cost savings on large infrastructure projects is mostly predicated on the idea that economies of scale create opportunities for 'synergies and integration' between different levels and roles that cut out redundancies, excess bureaucratic process, speed up development times, and increase the efficiency of conflict resolution and decision making. Also, as the more successful private sector consortia tend to be quite stable, it is possible to 'bundle' together a number of projects together into a single 
P3 contract (OAA, 2003). (As an early word of caution, bundling does give developers a potentially dangerous amount of power over the city from a contract negotiation standpoint though, as was the case with San Diego's downtown redevelopment plan which will be discussed in Chapter 4.)

'Partnering the supply chain' is another rationale. According to the OAA (2003), many analysts suggest that P3s would encourage positive relationships between traditionally 'adversarial' developers and governments, to create a 'partnering' mentality. These analysts argue that the traditional 'design-bid-build' approach pits the owners, builder, architects, subcontractors and local governments against each other. Building on the approach pioneered by the U.S. Army Corps of Engineers, it is thought that these adversarial relationships can be reversed by partnering all key players as equals from the start through an awareness of shared goals, objectives, incentives, and with clear mechanisms for resolving disputes.

While this doesn't seem to be the case in Ontario yet, in places with significant experience in $\mathrm{P} 3$, governments pursue $\mathrm{P} 3$ s with the expressly stated primary objective of improving service and quality to the public. To quote the Wales Minister of Finance: "the relationship with the private sector should be based on partnerships that improve services rather than just arrangements to access finance." (OAA, 2003).

Through P3s, the public sector is also seeking to transfer risk and responsibility to the private sector. Even if those risks cannot be fairly managed by the private sector - such 
as risks from unforeseen environmental conditions or other uninsurable risks. As a result, the builder might charge a higher price to address the additional risk responsibilities that are seen as inappropriate and/or unpredictable (OAA, 2003).

Of course, especially in Toronto and Ontario, some governments publicly base the decision to use P3 procurement in ideological reasons. While it's not unnatural to let beliefs initiate a course of action However, the P3 process is not universally applicable and any application of the model must be backed by a less than subjective rationale.

\subsection{The Success of P3 Overseas}

To clarify the fact that all P3s are not created equal O'Reilly (2003) interviews Ontario Superbuild Corp. president David Lindsay about the success of the British run Private Finance Initiative (PFI), which attracts private-sector expertise and funding to construct and operate select public facilities. In the UK, using traditional public procurement, 70 percent of comparable projects were late and 73 per cent came in over budget. Using $\mathrm{PFI}, 78$ per cent were on time, with the few that missed the completion date only late two months or less and only 22 per cent were over budget. Virtually all of the project managers said they were satisfied with the quality of the work - a dramatic change from past public projects in the UK.

However, as was the case in Toronto, the build and architectural quality of the first wave of PFI projects was broadly criticized by professionals and the public. As UK builders 
and architects have gained experience with the program, adjustments to the PFI process have been made to give more weighting to design issues and encourage better, rather than compromised design (OAA, 2003).

\subsection{Current Public Opinion of P3s in Ontario}

Canadian Business (2005) goes on to report that because of the perceived motivations (saving money at any cost) and the all-to-often end result (private corporations profit; public benefits are few), P3s are widely associated with neo-conservative political ideology. The strong public resistance to P3s in general by local unions and labour groups, whose collective agreements risk being opened up and changed, also feeds this characterization.

A major disadvantage in proving P3s will work today - especially in Ontario - is that they are still in their infancy, and new projects will be proposed in an environment where private partnership is associated with political ideology (oftentimes fairly so) and where failures are more easily recalled than successes (O'Reilly, 2003). Ideally, the use of a P3s should be seen of just one tool among many of developing good communities and cities, rather than as the value laden manifestation of any ideology. P3s are not a good fit for every project, and every $\mathrm{P} 3$ is unique because it revolves around unique physical, social and environmental conditions and thus, should also be considered as such. 
O'Reilly's (2003) paper concludes with the sentiment that in many ways, the blanket opposition to P3s in general by the public is misplaced. Fundamentally, what is important is to make sure the public gets the service it needs and wants, regardless of who owns the lease on the building. When the primary rationale behind any form of partnership is primarily short-term cost savings rather than improved quality and public benefit, skewed incentives are easily created which lead to unsustainable and imbalanced relationships between sectors - as was the case in Brampton. Regardless of build model, it is high quality design and construction that always turn out to be the best 'value for money' (OAA, 2003).

Chapters 3 and 4 of this study will demonstrate how - unlike the previously mentioned failing Brampton hospital and other such projects that have shaped a negative perception of P3s in general - the proposed P3 arrangement for vertical expansions creates positive incentives for both actors to deliver high public service quality, promotes positive long-term comınunity development and encourages ongoing equitable cooperation.

\subsection{The Additional Challenges of Air Rights Developments}

What sets vertical expansions apart from traditional suburban renewal \& redevelopments is the use of air rights development. Campbell's (2004) paper Creating Sustainable Air Rights Development Over Highway Corridors - discusses the construction of the Massachusetts Turnpike in Boston and presents an invaluable look 
at the unique challenges that developments using air rights must contend with. In this case study, the plan was to build a tubular decking above the Massachusetts Turnpike highway, and atop that construct new residential neighbourhoods. However, there are two negative factors associated with air rights development that significantly increase risk.

The first major issue is cost. For the Massachusetts Turnpike project, with air rights development came the added costs of building the reinforced tubed decking over the highways, extra exhaust fans, fire extinguishing systems and more. Depending on the load of the new building, the cost to build this way would be almost twice what it would be compared to terra-firma greenfield development. Also, in this case, the money and time saved by not having to excavate was not considerable enough alone to compensate for the increased costs.

The second substantial issue is the extended development time needed for air rights construction (typically one year would need to be added to the project). Because of this, risks increase due to market demand analysis, cash flow stability, incidence of labour disputes, and other economic factors being that much harder to predict and plan for.

Therefore, because there is less confidence of coming in on budget and being on . schedule, air rights developments are usually burdened with a higher lending premium. (Although, according to both Campbell (2004) and Dunham-Jones \& Williamson (2009), this premium is steadily decreasing as these projects become more commonplace.) 
To advance the feasibility of air rights development, Campbell's (2004) recommendations include: a robust and predictable regulatory framework to control the outcome of air rights development, design guidelines to ensure connectivity and contextualized development that also reflects realistic assumptions about financial feasibility and development intensity, and a systematic air rights lease negotiation process and framework that links leasing liabilities to future development revenues. For the purposes of demonstrating the feasibility of vertical expansion projects, it is vital that the specific cost issues and recommendations raised by Campbell (2004) be specifically addressed.

\subsection{Other Common P3 Pitfalls of Large Infrastructure Projects}

In addition to the equity measures mentioned earlier, there are also other important factors to consider in arranging a P3 to ensure that private interests are balanced with public community good in the fair and equitable way intended. There are three primary ways in which P3s, particularly those featuring ancillary development, can fall prey to private capture: (1) Poor contract design and vague terms during the formation of P3s, (2) flawed implementation of partnership agreements or their post contract renegotiation, and (3) the failure of public officials to properly evaluate the performance of private partners (Erie, Kogan, and MacKenzie, 2010). 
It is vital that the administration of a P3 agreement is as simple and reductionist as possible. The more organizations involved in management and administrative roles, the greater likelihood for confusion in the lines of authority and responsibility, along with an increased threat to the transparency and public accountability of the process (Erie, Kogan, and MacKenzie, 2010). Poor contract design strongly correlates to the balance of power between governments and developers. In cases where the city is strongly reliant on the developer, but the developer gains little but upfront payment from the city, private actors will be able to negotiate for vague responsibilities and commitments on the back end, while the city's costs are fixed and immediate (Erie, Kogan, and Mackenzie, 2010).

\subsection{Regarding Post-Construction P3 Management Issues}

Based on research from public-private partnerships in education, Smith and Wohlstetter's (2006) research is mostly themed around the post-construction or serviceoriented management side of the P3. Chiefly, actors must understand the challenges, or costs, of partnerships. Common among these costs are the reduced autonomy that comes from operating in conjunction with another organization, structural barriers to working together and the time and financial costs of working together. To deal with these costs, an accountability plan can be used to guide the work of a partnership and provide a framework by which to evaluate success. Formal documents of this nature generally establish the outcomes for which each member of the partnership is responsible, outline to whom the actors are accountable and specify the consequences of failure to meet the 
established goals. In chapter 4 of this report ('The Proposed P3 Design for Vertical Expansions'), Wohlstetter's exposition of a framework for evaluating P3 success will be used as an invaluable resource to guide the evaluation of vertical expansion operation efficiencies. 


\section{Chapter 3}

\section{The Feasibility of Vertical Expansions}

\subsection{The Benefits of Vertical Expansions to Both Local Community and}

\section{to Wider Urban Planning Objectives}

"Libraries are rare common ground on the fractious map of democracy, a place where traditional ideas of bootstrap self-improvement meet liberal ideas of open access and equal opportunity. Few encounters with local government - a labyrinth of red tape, taxes, frustration and long lines under fluorescent lights - feel so good as an afternoon in a well-run library. Without lecturing or hectoring or cheap rhetoric, they build consensus and commitment to self-governance." - Philip Kennicott - Washington Post, 2005

Vertical expansions of public community assets are particularly important in the communities identified earlier. Citizens see these buildings as a major part of the community infrastructure, open to everyone as a valuable and safe indissoluble resource. The services they provide are vital to new immigrants, the newly jobless, children, at-risk youth, and more, without costs, commitments or return expected (Marchese, 2005). 
Especially in the potential communities identified, it is the case that public services cannot meet capacity demands at current funding levels (CSPC, 2003). Over the past decade, substantial funding cuts alongside simultaneous increases in demand for services have resulted in dramatic understaffing, cutbacks in facilities improvement, and a funding shortfall for repairs and maintenance of buildings and information technology systems (Clutterbuck and Howarth (2002), Toronto Parks and Recreation (2011) \& CSPC, 2003). Turning this situation around requires ongoing investment. Unfortunately, over the last decade, fuelled by provincial side-loading and municipal inaction, barriers to access and participation have only increased (Clutterbuck and Howarth, 2002).

\section{How Vertical Expansions Increase Local Community Access to Services}

Private vertical expansion atop community buildings provide much needed public service funding in two ways. In exchange for the redundancy benefits and reduced land costs, the building developer will provide one-time capital funding which can be used to fund facilities expansion, public realm improvements and clear maintenance backlogs. Afterwards, a significant portion of property taxes and resident maintenance fees will be sent to the public service as ongoing funding which will take a lot of the operating strain of these services. What this loosening of the belt means for both new and existing residents of the community are: increased accessibility through higher program capacity and reduced or eliminated user fees, greater latitude to create programs for underserved demographics, and the ability to keep facilities in a state of good repair. The P3 agreement between the two partners is designed in such a way that public 
sector actcrs - with their greater experience and comparatively altruistic motivations will still administer and provide the entirety of the service.

\section{Where Vertical Expansions Fit In with Government Planning Objectives:}

"All levels of government are under pressure to meet public infrastructure needs.... Innovative, alternative partnership arrangements that protect the public interest; and the strategic staging of infrastructure investments are all required to respond to these challenges."

- Places to Grow Plan, 2006

The Provincial Places to Grow Plan reinforces the notion that neglect and insufficient funding for public infrastructure needs have been a decades long pattern (Ontario, 2006). The guiding principles of the growth plan, in section 1.2.2, state that we need to:

- Optimize the use of existing and new infrastructure to support growth in a compact, efficient form

- Provide for new approaches to manage growth that recognize the diversity of communities

- Promote collaboration among all sectors - government, private and non-profits and residents 
Vertical Expansion projects meet these ambitions head on by taking full advantage of pre-constructed redundancies, mutually beneficial $\mathrm{P} 3$ design, and a local community influenced physical design approach. Air rights projects, in general, are emerging as a beneficial type of development that promotes revitalization and can be more sustainable that traditional redevelopment initiatives (Campbell, 2004).

\section{Kickstarting a Virtuous Cycle in City 3 Neighbourhoods}

In the 'city 3 ' area of the inner-city suburbs, there is a vicious cycle of urban sprawl, income segregation, and jurisdictional disparities encouraged by unfavorable economic conditions including weak access to services and low quality amenities (Hulchanski, 2000 and JunJie, 2010).

Vertical expansion projects, which build up critical population density in a key community area, can act as a type of 'urban acupuncture' (Bedford, 2011) to kickstart a virtuous cycle improving local busiriess success, promoting a more compact urban spatial structure, and increasing the economic viability of high quality transit provision (JunJie, 2010 and Filion, 2000 and Canadian Urban Institute, 2005).

\section{Improving Neighbourhood Quality of Place and Uniqueness}

In the previous Chapter, we looked at the uniqueness and innovativeness of air rights development as a potential financial risk. On the other hand, these projects can also be 
an opportunity to create unique architectural experiences that build on and enhance local character of place and the regional context of each suburb. Identity is all too often a fundamentally lacking commodity in suburban environments and public buildings by adding the additional residential functions, even more modest architecture can generate and express identity (Pyo, 2009). Going forward, an engaged and communityoriented neighbourhood identity strongly influence planners' ability to implement the progressive planning values the often espouse (Grant, 2009).

\section{A Virtuous Cycle Attracts Local Business and Encourages their Success}

Community centres are prime catalysts for urban and neighbourhood development through their ability to attract people and their reputation as safe and stable community assets (Urban Libraries Council, 2011).

A study conducted by the Canadian Urban Institute (2005) on how businesses decide where to locate revealed that businesses and developers consider a wide range of factors beside the most commonly cited property tax differences. Businesses also look for local economic draws such as good urban design, people on the street, local labour force, amenities \& services, and location prestige (Canadian Urban Institute, 2005). The virtuous cycle that vertical expansions can kick off targets many of these economic pull factors (namely, density, amenities and a local labour force aided by the job skills upgrade and new immigrant services that libraries provide), and creates an environment where the rest can eventually be developed. 


\subsection{Evaluating Private Sector Feasibility using the Bontje Model}

For private sector actors to become interested in the potential for vertical expansion projects and enter into equitable P3 arrangements, it is necessary to demonstrate how these projects carry inherently low risk and high reward opportunities. To accomplish this, I will turn to the 'Bontje model' used by many AEC (Architecture, Engineering and Construction) firms to preliminarily assess risk and feasibility (Houben, Lenie and Vanhoof, 1999). In its simplest form, the Bontje model assesses feasibility through five management areas - the market, the money, the production, the people, and the environment (Houben, Lenie and Vanhoof, 1999).

\section{The Market}

Developers of vertical expansions benefit from the marketable locational advantages of the identified potential sites which are located near other desirable amenities such as shopping malls, schools, and parks. The city's own residential property assessment criteria partially supports this assumption; properties located near desirable amenities such as golf courses and green spaces are assessed a higher market value (MPAC, 2009).

Especially in inner suburban communities where greenfield development opportunities have mostly been swallowed up by single detached subdivisions and townhomes, and where populations are increasingly made up of empty-nesting seniors and newly mobile 
young adults (Hulchanski, 2010 and Moore, 2011), developers have the opportunity to reach new markets by providing - more lucrative - higher density living to the people it could appeal to most, in communities they are already familiar with and identify with.

The Money

For private sector actors, the fiscal feasibility of projects is of great importance. For most projects that use air rights the major deciding factor is cost (Campbell, 2004). The Market demographics (presented above) and Environmental locational advantages (presented below) and the previously built-form redundancies (i.e. prebuilt parking, amenity space, internal and external infrastructure) associated with the identified potential sites are a definite advantage for these projects.

However, there is often a premium associated with air rights construction for new development, these include constructability premiums, additional building construction complexity in addition to conventional building costs. Because the identified potential sites are filtered for basic structural criteria (flat roofs and 1-2 story low height), the complexity of construction should be drastically reduced, alongside the cost premium (Campbell, 2004).

There are also significant time costs that come with air rights development (Campbell, 2004), these lead to a host of uncertainties including interest rate risk in the construction financing, and reduced certainty about the market \& demographic conditions to which 
the development is targeted (Campbell, 2004). Nevertheless, project financing risks for air rights projects are decreasing as the financing and development communities are gaining experience with evaluating mixed-use public-private deals and suburban intensification projects (Dunham-Jones and Williamson, 2009). Regarding, the steadiness of the market and demographic conditions that the development is targeted to (increasing numbers of empty nesters looking to age in place, and young adults looking to move out for the first time), according to Hulchanski (2010), the demographic trends that exist in 'city 3 ' - where all the identified potential sites are located - are projected to only expand over time unless drastic change occurs. To further reduce time-based costs, the negotiations for the $\mathrm{P} 3$ regarding design, form, and fit could contribute towards expediting planning approval for the project. That is, the most immediately accessible savings from $\mathrm{P} 3$ alliances and partnering will come from a reduced requirement for tendering (OAA, 2003)

Whether the marketability, and redundancy benefits make up for any additional costs associated with air rights development needs to evaluated on a per site basis. However, both the site selection criteria and P3 design are set up to to strongly encourage the likelihood that the project will be profitable.

\section{The Production}


The construction of the project benefits greatly from the existing redundancies that already exist in the space that the developers do not need to build or buy the land for. These include:

- The pre-existing generously sized parking lots that do not need to be dug and paved

- Structural concrete footing columns that do not need to be excavated and poured

- Private amenity spaces (such as common rooms, fitness centres, and swimming pools) that do not need to be built or maintained

- Internal infrastructure (including the piping/wiring in of utilities of the street)

- External infrastructure (such as connecting to roads and landscaping)

The side benefits of this is that the money saved by the developer offsets the higher costs of increased construction complexity (Campbell, 2004), the rest would be used to add value to the shared public amenities as per the terms of the P3 arrangement, and by doing so improve the value \& appeal of the new development.

\section{The People}

In this case, considerations of people would primarily be an assessment of the benefits and frictions that dealing with the public sector actors involved in the P3 would bring (Houben, Lenie and Vanhoof, 1999). Toronto Parks and Recreation, the Toronto Public Library Board and the Association of Community Centres are the public-sector 
management groups closest to the identified community buildings. As such, one or more of these bodies is most likely to be the public sector partner on any potential project.

Due to the simple and reductionist design of the P3, where public sector actors are fully responsible for the management of public facilities and the private sector actors are fully responsible for the management of private facilities, it is transparent to all actors that they will not be responsible for more than they normally would as compared to the traditional development scenario. In the case of the private actor, there would actually be some reduction in responsibilities because existing redundancies (such as amenities) are managed by existing public actors. Of course, as mentioned in the P3 design section earlier, the ongoing operating costs saved by the developer are levied towards funding shared public amenities and services.

In similar circumstances, existing residents have expressed concern about gentrification effects of the new development (Campbell, 2004). In such cases, it is important for the developer to willingly involve the community, and keep them informed, as much as possible. Precedence for such progressive developer attitude and outlook could be seen in air rights intensification development projects in the residential neighbourhoods of Copley Square, Boston (Campbell, 2004). 
The Environment

Community Centres and Libraries generally are clustered nearby other locational advantages that appeal to homebuyers, such as schools, shopping malls, and recreation services. The potential project sites identified in the Site Selection section earlier show this to be the case as well. Wider environmental assessment factors include the strength of the economy and housing market which are highly temporal and outside of the scope of this report (Houben, Lenie and Vanhoof, 1999).

Thus, assessed through the five key management areas used in the Bontje model, there are certainly cost challenges associated with increased construction complexity (Campbell, 2004), but there are also numerous direct \& measurable economic benefits. Additionally, many of the risk factors that normally plague air rights development are significantly diminished by stable suburban market trends (Hulchanski, 2010) and an ever-increasing understanding of suburban intensification projects (Dunham-Jones and Williamson, 2009). 


\subsection{Specific Considerations are Needed for Projects to Get Off the}

\section{Ground}

\section{Pre-Zoning is Needed to Encourage Creative Development}

It is unrealistic to expect developers to spend hundreds of thousands of dollars on the work required to design and propose a vertical expansion project to risk it being scrapped or needlessly delayed by NIMBY groups, conservative political agendas or planning restrictions or other use controls that were not enacted with innovative developments in mind (Campbell, 2004 and Moore, 2011). Suburban planners across the city phrase it differently, but all essentially desire their suburbs to become cities (Grant, 2009). If zoning by-laws are sterilizing the vital life of a city, then removing them can stimulate the same vibrancy that created the historic downtown cores (such was the case at King \& Spadina and King \& Parliament) (CMHC, 2002 and Marchese, 2005). Thus, the required zoning for vertical expansion sites needs to be delivered ahead of time (Moore, 2011).

\section{To Ensure P3 Equity, Cost Assessment Sophistication is Critical}

Because air rights development is generally risk, complicated and uncommon, information is a key tool for government not only in controlling and encouraging this type of development (Campbell, 2004), but also to ensure an even footing with the privatesector during P3 negotiations (Erie, Kogan, and MacKenzie, 2010). Being able to 
independently assess reasonable private-sector costs gives the city a better seat at the negotiating table (Erie, Kogan, and MacKenzie, 2010). Some cities have also created air rights development 'guidelines' which purportedly act as a form of soft regulation and information (Campbell, 2004).

\section{There Needs to be a Real Commitment to High Quality Design}

"Jack Diamond of Diamond+Schmidt Architects: 'recognition of the value of good design and the intent to achieve it are the underpinnings of any significant improvement. But it will take the concerted, coordinated, and prolonged effort of owners, architects, regulators and citizens - groups that are normally fragmented.' "“

- Marchese, 2005)

Air rights development requires a distinct understanding of urban design and close attention to existing neighbourhood context (Campbell, 2004). Because of the public nature and perception of libraries and recreation centres, high quality architecture is vital for the project to achieve the intended wider community revitalization and urban acupuncture effects that kickstart the virtuous cycle. Good design also tangibly and measurably increases neighbouring property values which may encourage other higher density redevelopments (Marchese, 2005). 


\subsection{Site Selection Criteria and Results}

The goal of the site selection criteria is to find the community asset sites where there is most need for service capacity enhancement, which have potentially marketable locational advantages and a underdeveloped built form context. These are also sites where urban acupuncture measures have the highest potential for positive community effects (JunJie, 2010).

To identify these sites, I will be applying the following criteria to a GIS analysis. A potential site must meet all the following requirements to for inclusion:

1. Sites must be either a recreation centre or library - or both, as in the case of Malvern community centre. These sites also cannot be schools.

2. Sites must be in the inner-suburban area delineated as 'City $\mathbf{3}^{\prime}$ ' by Hulchanski (2010). These areas face declining incomes and higher minority populations - those most in need of services that increase community integration and provide support. City 3 also has a higher percentage of young people, predominantly low density form, and struggling local economies). Program use in these centres is extremely high and cannot be sustained at current funding levels (CSPC, 2003). 
3. Sites must have high potential marketability. For the purposes of this thesis, to be considered 'marketable' sites must be within walkable distances (within a $0.5 \mathrm{~km}$ radius) of three other desirable amenities such as other community centres, schools, parks and shopping malls.

The assumption here is that marketability, measured here through easy access to desirable amenities, will increase developer motivation and the potential financial success of the project for private-sector actors.

4. Physical site design considerations need to be taken into account. Buildings must be standalone structures, low rise ( 2 stories or less) and must have a mostly flat roof so as to be structurally and architecturally amenable to cost-effective vertical expansion.

5. Finally, to further refine the results, the computed walk score (from www.walkscore.com) will be used as a proxy measure for relative property values between the sites. The positive correlation between walk score and property values is asserted by CEOs for Cities (2009). Like with marketability, the assumption is that, suburban areas with higher existing property values are more attractive to developers and potential residents. 


\section{Site Selection Results:}

Using criteria one to four above, sixteen potential sites ripe for vertical expansion projects were identified across the city: 


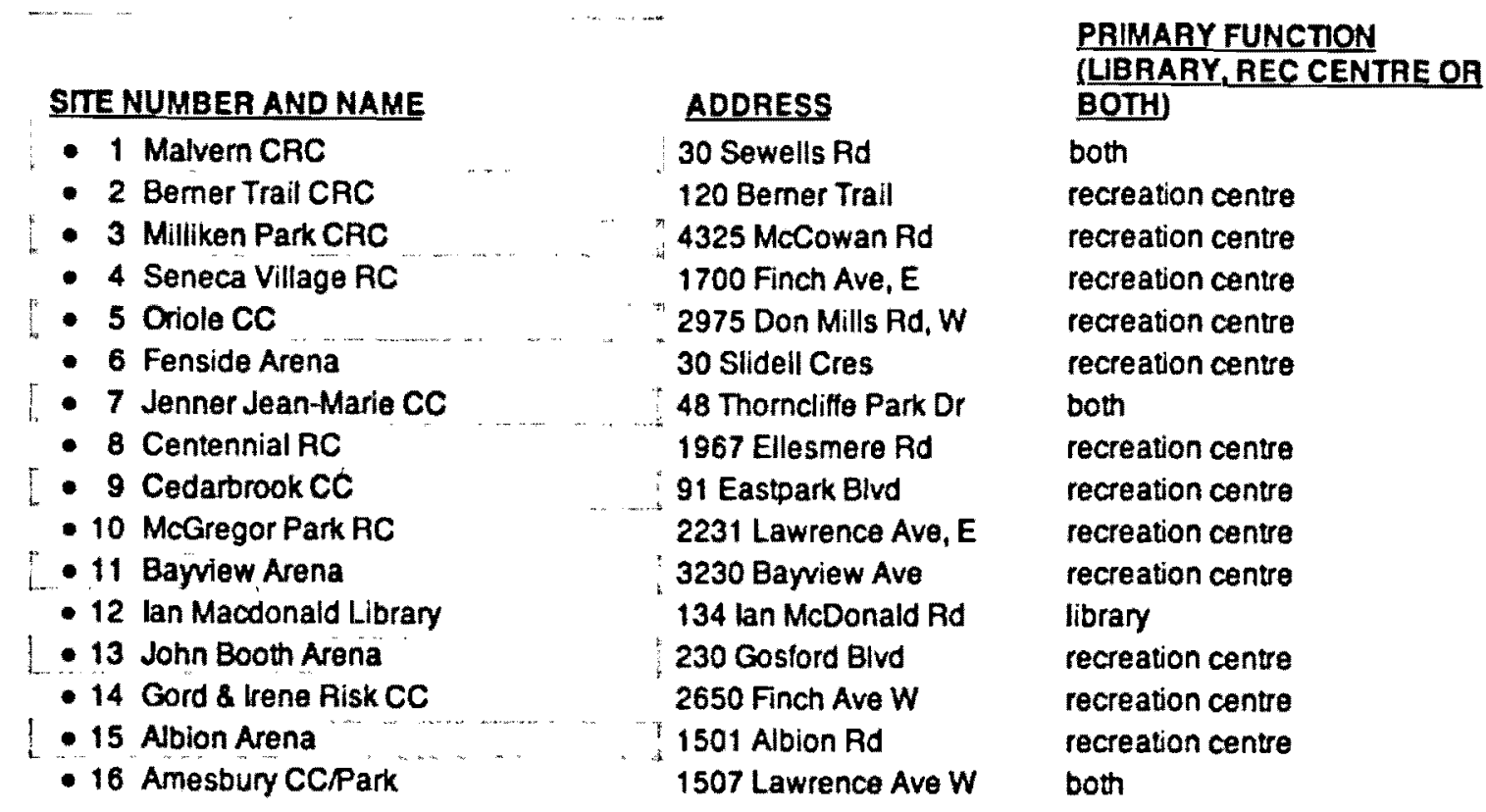

Numbered site selection map showing identified sites and nearby marketable locations

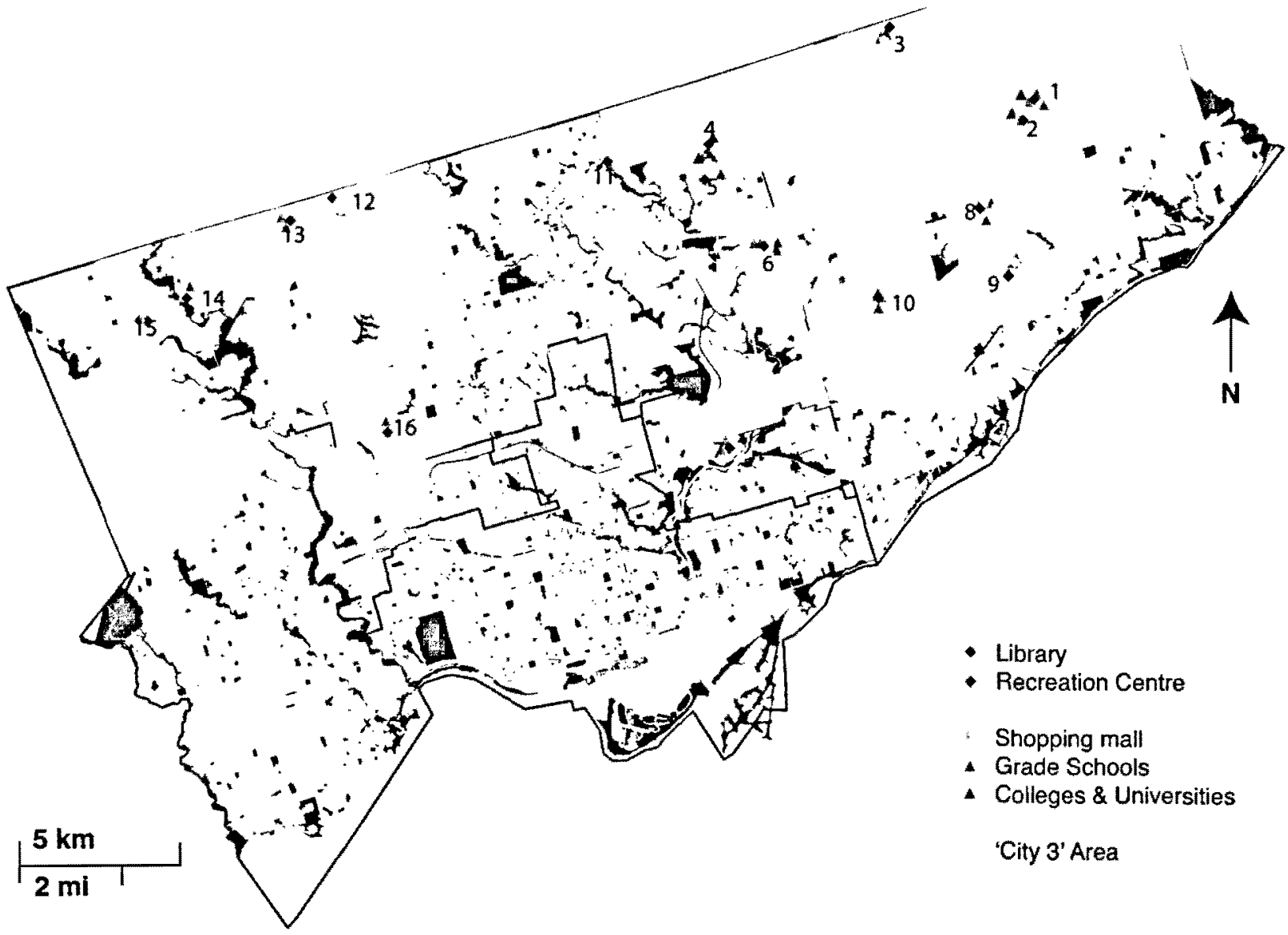


For the fifth and final criteria, the walk scores for each of the 16 above sites is displayed below:

\begin{tabular}{|c|c|}
\hline SITE NUMBER AND NAME & WALK SCORE \\
\hline 1 Malvem CRC & 70 \\
\hline 2 Bemer Trall CRC & 50 \\
\hline 3 Milliken Park CAC & 70 \\
\hline 4 Seneca Village RC & 65 \\
\hline 5 Oriole CC & 90 \\
\hline 6 Fenside Arena & 73 \\
\hline 7 Jenner Jean-Marie CC & 68 \\
\hline 8 Centennial RC & 75 \\
\hline Cedarbrook CC & 83 \\
\hline 10 McGregor Park RC & 78 \\
\hline 11 Baylew Arena & 55 \\
\hline 12 Lan MacDonald Lbrary & 52 \\
\hline 13 John Booth Arena & 62 \\
\hline 14 Gord \& Irene Risk CC & 48 \\
\hline 15 Albion Arena & 72 \\
\hline 16 Amesbuxw CC/Park & 67. \\
\hline
\end{tabular}

\footnotetext{
WALK SCORE DESCRIPTION (from walkscore.com)

90-100 Walker's Paradise - Daily Errands do not require a car.

70-89 "Very Walkable - Most errands can be accomplished on foot.

50-69 Somewhat Walkable - Some amenities within waiking distance.

25-49 Car Dependant - Few amenities within walking distance
}

Thus, while all sixteen pilot sites meet the criteria for vertical expansions, sites with the highest walk score - and by proxy, the highest property values - are the least risky development sites with the highest potential chance for economic success. 


\section{Chapter 4}

\section{Proposed P3 Design}

\subsection{The General Arrangement of the P3 used in Vertical Expansions to}

\section{Ensure Equity}

The most appropriate type of P3 for Vertical Expansions is a Design-Build-FinanceOwn-Operate (BDFOO) for Mixed Use Development. In a DBFOO, the private sector not only provides financing for the capital cost of the expansion, but as a result owns the expansion section of the building. Because they own it, the private owner is also obligated to provide the standard condominium services and maintenance to tenants, with the exception of anything related to the below shared-space amenities. In this case, both the public service and private residential space are partners working together towards the same goal - neither controls or manages the other, but both sides equally benefit from the collusion.

Specifically, the capital funds that developers no longer have to spend to develop already-in-place redundancies such as amenity space, parking, utility provision, and landscaping is redirected to Toronto Parks and Recreation (to be directed to the Association of Community Centres if necessary) and/or the Toronto Public Library Board. These funds should be spent on capital project expansions (such as new 
swimming pools, gymnasiums, library IT infrastructure, etc.), energy efficiency upgrades and to clear the state of good repair backlog (Toronto Parks and Recreation, 2011). Surplus funds, along with negotiated section 37 benefits and revenue from land value capture can also be used on urban design improvements to adjacent public realm spaces and streetscapes to enhance both the immediate marketability of the area and the potential urban acupuncture effect.

Citizens see the library as a public city function so it is important that it continue to operate that way (Marchese, 2005). Because the administration of maintenance and services of the public side remains in the hands of experienced public sector actors, there is likely to be greater public accountability in how funds are spent, and an avoidance of the types of distorted incentives that lead to inequities (Erie, Kogan, and MacKenzie, 2010).

Supplementary continual operating funding for the public side functions will be provided through a large share of the maintenance fees and property taxes charged to residents. These fees should be in line with market standards for condominiums with similar amenities, but the specific value of these fees must be agreed upon upfront rather than left to chance. P3 cases, where private actors have vague and flexible commitments often act as a loophole to promote inequity (Erie, Kogan, and MacKenzie, 2010). These fees will be used to expand the breadth of services offered, increase program capacity, fund ongoing maintenance, reduce or eliminate user fees, and dramatically decrease rental costs for community social functions. 


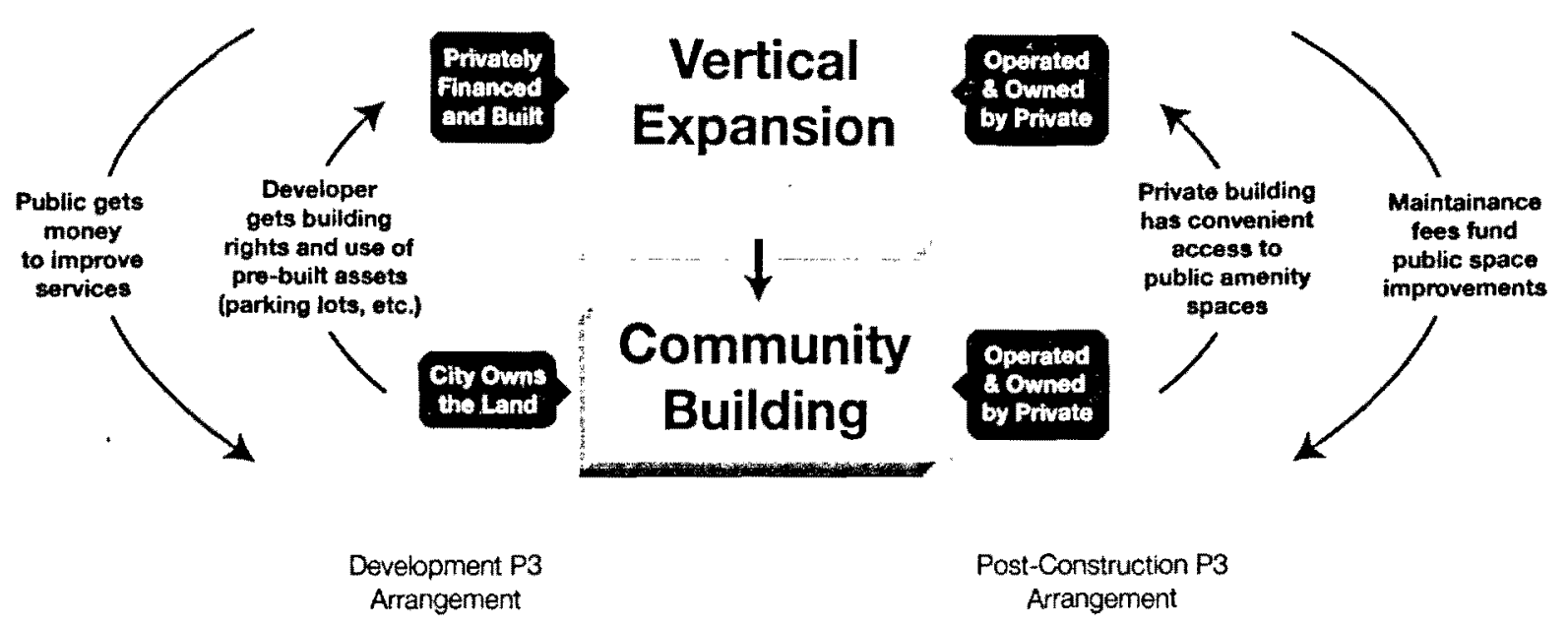

\subsection{Additional Considerations Made to Avoid Potential Pitfalls}

To avoid the three primary ways in which P3s - particularly those featuring ancillary development - can fall prey to private capture, the vertical expansion P3 aims to align the incentives and actions of both players in a mutually reinforcing way. The city's main commitment is to use developer capital and operating funds towards the best interests of the public amenity, which also directly benefits the attractiveness of the private development, and it is the developer who pays the immediate new development costs in exchange for the locational and service benefits of building on top of it.

Both players strongly rely on each other to provide valuable short and long-term incentives which helps assure that neither player is in an overly advantageous position 
to renegotiate for unfair terms later on. The result of this mutually beneficial symbiosis is that issues of public policy and public interest will not become submerged by the demands of the market (Wettenhall, 2003).

Another measure that can ensure the city's strong position in negotiations is to create an accountability plan which clearly states all requirements and responsibilities up front, provide a framework by which to evaluate success, and to delineate the consequences of failure to meet established goals (Smith and Wohlstetter, 2006). Additionally negotiations should have both the structural analysis completed and a conceptual physical design proposed upfront to make certain that all stakeholders are clear about their roles and responsibilities (Erie, Kogan, and MacKenzie, 2010 \& Wettenhall, 2003).

\subsection{How P3 Success will be Evaluated}

Crucial to the $\mathrm{P} 3$ arrangement is the regular monitoring of the performance, equity and accessibility of public services by public officials (Smith and Wohlstetter, 2006). The purpose of these specific monitoring criteria would be to ensure that built contractual obligations are met on time, that the project and designs presented to the public are what is actually delivered, and that there is true equity in the public and private benefits promised. 
For pre-agreed upon capital improvements, it is easy enough to observe whether facility upgrades have been completed on time as expected, and that the maintenance backlog has been cleared as agreed upon.

To measure the effect of ongoing funding to the public service program offerings offerings, the city can use the same quantitative measures that Toronto Parks and Recreation and the Libraries already use to prepare fact sheets and service assessments (CSPC, 2003). These include:

- Whether user fees are drastically reduced

- An analysis of who is enrolled in new and existing programs (by income group, age and new immigrant status)

- Whether total program enrollment and service utilization has significantly increased - Comparing the size of wait lists and the time it takes for offered programs to fill up, to the states previous to the private expansion

- Comparing operating hours, to those before the development.

- Observing the number of new programs targeting youth and seniors

- Whether room rental space costs for community functions has decreased and whether the spaces are used equitably by both new and existing residents.

Additionally, qualitative interviews and survey studies regarding their opinions of the quality of services, new facilities and capacity increases can be conducted of public service staff and administration, as well as from community members. 
In order for a partnership to be sustained (and to inspire similar expansions in the other identified potential sites), benefits should ultimately accrue to both partners (Smith and Wohlstetter, 2006). For simplicity, the private building section will be treated, for the most part, like any other condominium. Private building owners are responsible for making sure new residents are happy with conditions not related to the public services on the ground floor. These residents can form condo associations, but they cannot negotiate for any preferential treatment from the public service.

In the similar case of the recent Regent Park redevelopment in downtown Toronto, this project was conceived of and developed in large part as a direct response to a specific set of problems (i.e poverty, crime and poor local employment opportunities). As a result, the success of the project will also be evaluated through their effectiveness at alleviating these problems (i.e. poverty reduction and improved employment opportunities, while keeping the rich demographic/social mix of the area preredevelopment (Hall, 2009).

The vertical expansions being proposed in this report differ from Regent Park in that, at this early stage, they are being proposed in this report as a system/model of intensification rather than a very targeted intervention for a specific single site. In the case of any vertical expansion proposal, additional evaluation criteria that consider individual site situational context is important. 


\section{Chapter 5}

\section{Analysis and Discussion}

It is hoped that this study, and the proposal of P3s for vertical expansions, will reveal new knowledge and improve understanding for decision makers contemplating smaller scale, single-facility based P3 arrangements. The proposed P3 management model of the new shared facility created through the vertical expansion project is purposefully reductionistic to clearly state roles and responsibilities in order to avoid complications and mismanagement that could otherwise occur. The requirements of public actors to ensure the creation of successful partnerships and how success and equity can be measured is also outlined above.

In addition to increasing much needed access to services and recreation opportunities for the community, vertical expansion projects increase density in established innersuburban neighborhoods where infill opportunities are scarce and, in the longer term, strongly contribute to smart growth objectives. Such interventions serve as urban acupuncture to stimulate a virtuous cycle including higher quality urban design, increased local business activity and increased residential density in Toronto (JunJie, 2010 and Canadian Urban Institute, 2005).

As discussed in Chapter 2.1, the history of P3s in Ontario is not particularly positive. Projects such as the Brampton Civic Hospital ballooned in cost and were criticized by 
their lack of openness and transparency. Regardless, vertical expansions are just one example of the move towards greater $\mathrm{P} 3$ use by over burdened municipal governments. Other examples include the recent Regent Park redevelopment using a P3 model very similar to vertical expansions and the proposed new Metrolynx regional transportation plan. In this case however, the likelihood of partnership success and maintained transparency are increased in smaller scale individual projects because the borrowing costs and profit requirements for a condominium (as compared to a hospital for example) are not overwhelming.

The negative public opinion of all P3s stemming from past failed projects and the opposition of urions and labour groups is largely misplaced. To reiterate the conclusions of the OAA (2003), what is important is to make sure the public gets the service it needs and wants, regardless of who owns the lease on the building. When the primary rationale behind any form of partnership is primarily short-term cost savings rather than improved quality and public benefit, skewed incentives are easily created which lead to unsustainable and imbalanced relationships between sectors - as was the case in Brampton. Regardless of build model, it is high quality design and construction that always turn out to be the best 'value for money' - which was the focus of the more recent Regent Park redevelopment plan. In essense the fundamentals of quality city building never change.

The cited advantages of $P 3$ delivery by provincial and municipal governments alike are cost savings (based on economies of scale and a reduction of bureaucratic red tape) 
and for 'partnering the supply chain' (that is, to create a 'partnering' relationship between developers and the city, rather than the tradition adversarial one).

Unfortunately, air rights developments carry with them unique additional challenges that must be overcome for feasibility. The first major issue is cost - in the case of the Massachusetts Turnpike highway discussed by Campbell (2004) - the money and time saved by not having to excavate was not considerable enough alone to compensate for the increased costs. The approach of vertical expansions to this issue is to increase the cost savings beyond skipping excavation. These additional cost saving redundancies include the ability to piggyback of existing amenity spaces, parking and utilities infrastructure. However, the specific cost assessments are beyond the scope of this report, but it stands to reason that the increased development complexity and cost will have increased feasibility on sites with higher land values. As seen below in section 6.3, this is a definite area for further research.

Similar P3 projects in the city such as the Regent Park redevelopment demonstrate that municipal ownership of potentially high value land is a desirable enough incentive to get private developers into negotiations. Like with Regent Park, the vertical expansion P3 is set up in such a way that the developers pay for all construction costs in exchange for access to that land (Hall, 2009).

However, Regent Park had the advantage of being in an excellent central residential location, it can be argued that making the same case in suburban areas with lower 
property values and increased design complexity would be more of a challenge. Even so, the primary pilot sites most recommended earlier on in this report have relatively good transit coverage, and are communities with nearby workplaces, retail and entertainment in walkable ranges. 


\section{Chapter 6}

\section{Conclusions, Recommendations and Areas for Further}

\section{Study}

\subsection{Conclusions}

The aim of this study was to analyze the feasibility of building private residential space on top of existing publicly-owned inner-suburban Toronto community centres and library buildings through a public-private partnership.

The numerous benefits and feasibility of vertical expansions to the community and government was validated by the potential ability to increase local access to services, compatibility with wider government planning objectives such as smart growth, and by the capacity to kickstart a virtuous economic cycle to increase quality of place. The appeal to private developers was demonstrated using considerations of the market, money, production, people and environment.

Using the criteria described in section 3.4, possible target sites where vertical expansion could best succeed were identified based on facility type, 'city 3 ' suburban status, potential marketability, and basic physical \& structural considerations. Using GIS analysis, 16 pilot sites were identified, which were further refined based on walk score 
(used as a proxy for property value) to identify the pilot sites with the highest potential for success.

A model for a reductionist and mutually equitable $\mathrm{P} 3$ arrangement for both the development and post-construction management was proposed and informed by the literature review of past $\mathrm{P} 3$ case studies.

\subsection{Recommendations}

In the research to propose and demonstrate the viability of vertical expansions, a number of Guiding Principles (GPs) were revealed which will serve as broader Recommendations for decision makers contemplating this and any similarly small scale P3-based urban intervention:

- Community-Oriented Guiding Principles for the Design of Vertical Expansion Projects:

GP1 - It is vital that a private space built upon a public one does not appear sterile or imposing and that it does not, in any way, take away from the perception of community buildings as being public, open, inviting and accessible to everyone. The architecture of libraries in particular is often an important part of civic pride and placefulness (Urban 
Libraries Council, 2011). The architecture of vertical expansions should act to only enhance the allure and uniqueness of place.

GP2 - The P3 arrangement should always give public sector actors the same authority and comprehensiveness to manage public services that they previously had. Private sector actors only provide funding. This keeps the agreement as simple as possible and allows for maximum transparency and accountability (Erie, Kogan, and MacKenzie, 2010).

- Market-Oriented Guiding Principles for the Design of Vertical Expansion Projects: GP3 - Private and public sector expectations and responsibilities must be stated up front. To reduce risk and encourage private-sector buy-in, many P3 arrangements give the developer a high degree of flexibility and allow the 'market success' of the project to determine what will be expected of them later. Such arrangements can act as a double edged sword that gives the private-sector a way out of honoring responsibility (Erie, Kogan, and MacKenzie, 2010 and Campbell, 2004).

GP4 - Vertical Expansion developments must contribute positively to the redun'dancies they take advantage of, but the benefits to the public amenity should likewise act to increase the value and appeal of the new development. The intent of the P3 is to foster a mutually beneficial relationship. 
- Political \& Planning-Oriented Guiding Principles for the Design of Vertical Expansion Projects:

GP5 - Due to the open, public nature of the existing community building, vertical expansions require special urban design scrutiny and attention to neighbourhood context

GP6 - Pre-Zoning is needed to encourage developers to take action

GP7 - To ensure P3 equity, the city needs to have a sophisticated understanding of the development costs involved

\subsection{Areas for further study}

Due to the limited scope and timeframe of this research, I had to use area walk scores for each pilot site as a proxy for property values. This was based on the assumption that high walk score areas also tend to have higher property values (CEOs for Cities, 2009). Ideally, a more direct indicator could have been used such as the average price per sq/ foot of land, which could be gathered using a spatially targeted random sample of realestate prices in each area - to name one method. 
Additionally, this research explored vertical expansions in a purely theoretical context, focusing primarily on planning feasibility and how the $\mathrm{P} 3$ arrangement would work. For proposals of real-world vertical expansions projects to carry more weight other contexts outside of the scope of this report should also be thoroughly evaluated. These include structural engineering issues and feasibility on a per site basis, as well as architectural and phasing strategies so that public facilities can still remain open during the construction period. 


\section{References}

Bedford, P. (2011). In a lecture on Februrary 3rd, 2011 to our graduate studio class.

Benfield, K. (2010). Smart growth principles for the 21st century. In Natural Resources Defense Council Staff Blog. Retrieved Feb 14, 2011 from http://switchboard.nrdc.org/ blogs/kbenfield/smart growth principles for th.html

Bunting, T. Filion, P. and Priston, H. (2002). Density Gradients in Canadian Metropolitan Regions, 1971-96: Differential Patterns of Central Area and Suburban Growth and Change. Urban Studies. v. 39(13). pp. 2531-2551

Canadian Business (2005). A bad time for good ideas. 78(13), 84-84. Retrieved from http://ezproxy.lib.ryerson.ca/login?url=http://search.proquest.com/docview/221439970? accountid $=13631$

Canadian Urban Institute. (2005). Business Competitiveness in the GTA: Why Toronto is Losing Ground. Accessed from: http://torontoofficecoalition.com/pdf/CUIBusiness Competitiveness.pdf

Campbell, B. E. (2004). Creating Sustainable Air Rights Development Over Highway Corridors: Lessons from the Massachusetts Turnpike in Boston. Retrieved from: http:/l dspace.mit.edu/bitstream/handle/1721.1/35695/60250140.pdf?sequence $=1$

CEOs for Cities (2009). Walking the Walk: How Walkability Raises Home Values in U.S. Cities. Retrieved from: http://blog.walkscore.com/wp-content/uploads/2009/08/ WalkingTheWalk CEOsforCities.pdf

City of Toronto. (2007). Staff Report: Association of Community Centres (AOCCs) Program Funding Sources. Retrieved from: http://www.toronto.ca/legdocs/mmis/2007/ au/bgrd/backgroundfile-745.pdf

City of Toronto Parks and Recreation. (2011). 2011 Recommended Operating Budget \& 2011 - 2020 Capital Plan. Retrieved from: http://www.toronto.ca/budget2011/pdf/ presentation 11 pfr.pdf

Clutterbuck, P. and Howarth, R. (2002). Toronto's Quiet Crisis: The Case for Social and Community Infrastructure Investment. University of Toronto: Centre for Urban and Community Studies. Retrieved from: http://www.urbancenter.utoronto.ca/pdfs/curp/ Clutterbuck 198 Toronto.pdf

CMHC. (2002). Residential intensification Case Studies: The King's Regeneration Initiative. Accessed From: http://www.cmhc-schl.gc.ca/en/inpr/su/sucopl/upload/TheKings-Regeneration-Initiative-Toronto-Ont.pdf 
CSPC - Community Social Planning Council of Toronto. (2003). Social Infrastructure and Vulnerable Communities. Retrieved from: http://www.urbancentre.utoronto.ca/pdfs/ elibrary/CSPC Social-Infrastructure.pdf

Doolittle, R. (Fri Jan 14, 2011). User fee hikes could raise cost of fun and fidelity. Toronto Star. Retrieved from: http://www. thestar.com/news/torontocouncil/article/ 921093--user-fee-hikes-could-raise-cost-of-fun-and-fidelity

Dunham-Jones, E. and Williamson, J. (2009). Retrofitting Suburbia: Urban Design Solutions for Redesigning Suburbs. John Wiley \& Sons: New Jersey.

Exner, U and Presser, D. (2009). Spatial Design. Birkhäuser: Basel.

Erie, S. P., Kogan, V., and MacKenzie, S. A. (2010). Redevelopment, San Diego Style: The Limits of Public-Private Partnerships. Urban Affairs Review, vol. 45(5). pp. 644-678

Filion, P. (2000). Suburban mixed-use centres and urban dispersion: what difference do they make? Environment and Planning. Vol. 33. pp. 141-160

Filion, P., Mcspurren, K., and Huether, N. (2000). Suburban Mixed-Use Centers: The Toronto Experience. Journal of Urban Affairs. Vol. 22(4). pp. 419-438

Front Seat (2011). Walk Score website. Retrieved from: http://www.walkscore.com/howit-works.shtml

Gilbert, E. (2009). Failing grade for public-private partnership hospitals. Canadian Medical Association Journal, 180(4). Retrieved from http://www.ncbi.nlm.nih.gov/pmcl articles/PMC2638045I

Grant, L. J. (2009). Theory and Practice in Planning the Suburbs: Challenges to Implementing New Urbanism, Smart Growth, and Sustainability Principles. Planning Theory \& Practice. Vol. 10(1). pp. 11-33

Hall, J. (2009). The new Regent Park - will it work?. U of T Research \& Innovation. Retrieved from: http://www.research.utoronto.ca/behind the headlines/the-new-regentpark-will-it-work

Houben G., Lenie K., and Vanhoof K. (1999) A knowledge-based SWOT-analysis system as an instrument for strategic planning in small and medium sized enterprises. Decision Support Systems. Vol. 26. pp. 125-135

Hulchanski, D. (2010). The Three Cities Within Toronto: Income Polarization Among Toronto's Neighbourhoods, 1970-2005. Retrieved from: http:/l www.citiescentre.utoronto.ca/Assets/Cities+Centre+Digital+Assets/pdfs/publications/ Three+Cities+Within+Toronto+Hulchanski+2010.pdf 
JunJie, W. (2010). Economic Fundamentals and Urban-Suburban Disparities. Journal of Regional Science, 50(2), 570-591. doi:10.1111/.1467-9787.2010.00665.x

Kennicott, P. (Friday, January 21, 2011) New libraries bring contemporary look to District neighbourhoods. Washington Post. Retrieved from: http://www.washingtonpost.com/wpdyn/content/article/2011/01/21/AR2011012102973.html

Marchese, I. (2005). Urban Issues and Politics: A Discussion with Jack Diamond. The Journal of the Ontario Association of Architects. vol. 13(1). pp. 11-13.

Moore, L. (2011). In a guest lecture held March 2nd for our graduate studio class (Leith Moore is a planner for the Sorbara group development company).

MPAC. (2009). Residential Property Assessment in Ontario. Retrieved from: http:// www.mpac.ca/pages english/pdf/residential property assessment br.pdf

OAA (2003). A P3 'Primer'. Retrieved from http://webcache.googleusercontent.com/ search?q=cache:kRfEmXRz29cJ:www.oaa.on.ca/client/oaa/OAAHome.nst/object/ P3/\$file/P3Primer.pdf+history+of $+p 3+o n t a r i o \& h l=e n \& g l=c a$

Ontario. (2006) Place to Grow: Growth Plan for the Greater Golden Horseshoe. Accessed From: https://www.placestogrow.ca/images/pdfs/FPLAN-ENG-WEB-ALL.pdf

O'Reilly, D. (2003). P3 projects aren't always practical, says superbuild chief: Despite benefits.. Daily Commercial News and Construction Record, 76(109), 1-1,5. Retrieved from http://ezproxy.lib.ryerson.ca/login?url=http://search.proquest.com/docview/ 224202464? accountid $=13631$

Pyo, M. Y. (2009). Advanced Public Design, Volume 3. Damdi: Korea.

Reily, J. W. (2000). The Language of Real Estate: Fifth Edition. Real Estate Education Company: Chicago.

Smith, J. and Wohlstetter, P. (2006). Understanding the different faces of partnering: a typology of public-private partnerships. School Leadership and Management. vol. 26(3). pp. 249-268.

Thompson, N., Kastner, J., and Paglen, T. (2009). Experimental Geography: radical approaches to landscape, cartography, and urbanism. Melville House: Brooklyn, NY.

Urban Libraries Council. (2011). Partners for the Future: Public Libraries and Local Governments Creating Sustainable Communities. Retrieved from: http:// urbanlibraries.org/associations/9851/files/0110ulc sustainability singlepages rev.pdf

Wettenhall, R. (2003). The Rhetoric and Reality of Public-Private Partnerships. Public Organization Review: A Global Journal. vol. 3. pp. 77-107. 
Zinnia, C. (2000). Retrofitting Suburbia: Transforming car-dependent subdivisions into transit-and pedestrian-friendly neighbourhoods. Alternatives Journal. Vol. 26(3). pp.19 